\title{
Perceptions of Prophylactic Mastectomy in Korea
}

\author{
Han Young Yoon, Jeong Su Shim, Jong Won Lee \\ Department of Plastic and Reconstructive Surgery, Catholic University of Daegu School of Medicine, Daegu, Korea
}

Background Increasingly, prophylactic mastectomy has been evaluated as a treatment of breast cancer. Hereditary breast cancer now accounts for approximately 5\%-10\% of all cases of breast cancer, meaning that the widespread implementation of prophylactic mastectomy may significantly reduce the occurrence of breast cancer. However, prophylactic mastectomy is rarely performed in Korea. Therefore, in this study, we assessed Koreans' attitudes toward and awareness of preventive mastectomy.

Methods This was a prospective study of a cohort of patients attending outpatient clinics and their relatives. Data were collected using self-administered questionnaires assessing sex, age, educational level, knowledge of breast cancer, understanding of prophylactic mastectomy, attitudes toward prophylactic mastectomy, and reasons for choosing prophylactic mastectomy. Results Sixty-five patients were included. Most patients (36.9\%) were between 40 and 49 years of age and $58.4 \%$ were college graduates. Only six respondents (9\%) understood prophylactic mastectomy, and 17 respondents (27\%) stated that they would agree to undergo prophylactic mastectomy if necessary. Reasons given for refusing prophylactic mastectomy included aesthetic concerns $(38 \%)$, the perception that it would not cure the disease $(26 \%)$, possible surgical complications (24\%), and financial cost (6\%).

Conclusions In this study, most of the respondents showed a poor knowledge of prophylactic mastectomy. Ultimately, it will be necessary to establish medical guidelines for patients with a high risk of breast cancer, with the objective of providing accurate information and proper treatment at hospitals.

Keywords: Prophylactic surgical procedures / Breast neoplasms / Mastectomy
Correspondence: Jeong Su Shim Department of Plastic and Reconstructive Surgery, Catholic University of Daegu School of Medicine, 33 Duryugongwon-ro 17-gil, Namgu, Daegu 42472, Korea Tel: +82-53-650-4581

Fax: +82-53-650-4584

E-mail: jsshim@cu.ac.kr

No potential conflict of interest relevant to this article was reported.

\section{INTRODUCTION}

In Western societies, public awareness of prophylactic mastectomy increased after Angelina Jolie, a famous actress, underwent prophylactic mastectomy. Prophylactic mastectomy is performed in the United States and Scandinavian countries more commonly than in Asian countries, and it is becoming an increasingly common procedure. However, prophylactic mastectomy is rarely performed in Korea, and information about prophylactic mastectomy is so limited that few breast cancer patients have a good understanding of it.

Breast cancer is a relatively common condition in developed countries. It is the most common type of cancer in the United States and the second most common type of cancer, after thyroid cancer, among all types of cancer that can occur among women in Korea. According to the Central Cancer Registry of the Ministry of Health and Welfare, cases of breast cancer accounted for $15.4 \%$ of all cancer cases in women in 2010 [1]. The incidence of breast cancer is increasing, and data from the projects registered by the Korean Breast Cancer Society show a total 
of approximately 17,000 breast cancer patients in 2010. Cases of hereditary breast cancer have been reported to account for approximately $5 \%-10 \%$ of all breast cancer cases, and it has been estimated that approximately 1,000 cases of hereditary breast cancer occur annually in Korea [2]. Hereditary breast cancer is notable because the preventive intervention of genetic testing can reduce the risk of both breast cancer and ovarian cancer $[3,4]$.

Recent studies of genetic mutations that lead to hereditary breast cancer, including the BRCA1 and BRCA2 genes, have led to an increasing number of studies on prophylactic mastectomy that have been reported in the mass media. As a result, women have become interested in genetic testing for hereditary breast cancer to determine the likelihood of breast cancer and in screening tests for those with a high risk of breast cancer. On the basis of the results of testing, women with a high risk of breast cancer can reduce their breast cancer morbidity by undergoing prophylactic mastectomy [5]. However, other methods of treatment may be superior to prophylactic mastectomy in some cases. For example, young women with no experience of breastfeeding may require other preventive methods, such as simple radiography on a regular basis, instead of prophylactic mastectomy [6] .

As stated above, breast cancer is typically a condition of developed countries, common among women, and is increasing in incidence annually. Cases of hereditary breast cancer account for as many as $5 \%-10 \%$ of all cases of breast cancer, and a screening test that involves genetic testing can identify patients with a high risk of breast cancer. Since high-risk patients can reduce morbidity by undergoing prophylactic mastectomy, it is important to provide correct information about prophylactic mastectomy as well as genetic testing for hereditary breast cancer. Neither prophylactic mastectomy nor genetic testing for hereditary breast cancer is commonly performed in Korea, and limited information is available about these options for high-risk patients. Furthermore, no studies have assessed levels of knowledge and awareness of prophylactic mastectomy among Koreans. We therefore conducted a prospective survey evaluating awareness, knowledge, and attitudes regarding prophylactic mastectomy and hereditary breast cancer among Korean women.

\section{METHODS}

\section{Subjects and research plan}

This prospective study was conducted on a cohort of patients and their relatives visiting the outpatient clinics of general surgery departments from October to December 2013. Before conducting the survey, consent was obtained from each subject. The questionnaire was composed of 20 items: nine concerning general knowledge of prophylactic mastectomy, six concerning atti- tudes toward prophylactic mastectomy, and five concerning the general characteristics of the respondents.

\section{Sample size estimation}

It was found that a minimum of 48 responses were necessary, using the equation $n=\left(\frac{z_{\alpha} / z^{\sigma}}{d}\right)^{2}$ to calculate the sample size, with a significance level of 0.05 , a standard deviation of 7.00 on the basis of a literature review, and an allowable error of 2.00 [7]. Here, $z_{\alpha / 2}$ is the value for the point with $100(\alpha / 2) \%$ in a standard normal distribution curve with a mean of 0 and variance of $1, \sigma$ is the value for the standard deviation, and $d$ is the value for allowable error. However, the actual necessary sample size was estimated to be at least 58 , taking into account a $20 \%$ drop rate caused by a combination of unreturned questionnaires and inappropriate responses. Of the 145 questionnaires that were distributed, 116 (approximately 80\%) were returned. The data from a total of 115 questionnaires were finally analyzed, with the exception of one questionnaire with missing items and inappropriate responses.

\section{RESULTS}

\section{General characteristics of respondents}

A total of 115 respondents were included in the study, of whom 50 were men and 65 were women. Ninety-two respondents (82\%) were 30-59 years of age. The most frequent level of education was college graduation (63\%), followed by high school, middle school, and elementary school graduation. The most frequent type of profession was clerical work (46 respondents; $40 \%$ ), followed by professional work (31 respondents; $27 \%$ ), housework, day labor, and others (Table 1).

\section{Knowledge of prophylactic mastectomy}

Most respondents had never heard of prophylactic mastectomy or had heard about it once ( $86 \%$ ), and only seven respondents had a detailed knowledge of prophylactic mastectomy. The participants had a generally similar level of knowledge of its effectiveness and complications: 96 respondents (83\%) and 112 respondents (97\%) had never or just once heard about the effectiveness and complications of prophylactic mastectomy, respectively, demonstrating that neither the effectiveness nor the complications of prophylactic mastectomy are widely known. In contrast, 31 respondents (27\%) had a basic knowledge of hereditary breast cancer and eight (7\%) had a detailed knowledge, resulting in a total of 39 respondents (34\%) who had some degree of knowledge of hereditary breast cancer (Table 2). 


\section{Attitudes toward prophylactic mastectomy}

Sixty-one participants (53\%) responded positively regarding their willingness to consider genetic testing (e.g., BRCA1 or $B R C A 2)$ and 11 respondents (9\%) stated that they would be sure to receive genetic counseling. Seventy-two respondents $(62 \%)$ had a positive attitude toward genetic testing.

Sixty-two participants (54\%) responded negatively regarding their willingness to consider prophylactic mastectomy, and 16 (14\%) responded that they would never choose to undergo prophylactic mastectomy even if they were at a high risk of breast cancer. Seventy-eight respondents (68\%) responded negatively regarding their willingness to consider prophylactic mastectomy even if they were at a high risk of breast cancer. If prophylactic mastectomy was expensive, costing ten million won or more, 72

\section{Table 1. General characteristics of respondents}

\begin{tabular}{|lccc|}
\hline \multirow{3}{*}{ Characteristic } & \multicolumn{3}{c|}{ Sex } \\
\cline { 2 - 4 } & Male & Female & Total (\%) \\
\hline Age (yr) & & & \\
$20-29$ & 13 & 6 & $19(17)$ \\
$30-39$ & 17 & 19 & $36(31)$ \\
$40-49$ & 9 & 24 & $33(29)$ \\
$50-59$ & 9 & 14 & $23(20)$ \\
$\geq 60$ & 2 & 2 & $4(3)$ \\
Total & 50 & 65 & 115 \\
Education & & & \\
None & 0 & 2 & $2(2)$ \\
Elementary school & 1 & 5 & $6(5)$ \\
Middle school & 3 & 9 & $12(10)$ \\
High school & 12 & 11 & $23(20)$ \\
University or higher & 34 & 38 & $72(63)$ \\
Total & 50 & 65 & 115 \\
\hline
\end{tabular}

participants (63\%) responded negatively regarding their willingness to consider it, and 29 participants (25\%) stated that they would never be willing to undergo prophylactic mastectomy. Thus, a total of 101 respondents ( $88 \%$ ) gave a negative answer to these items, showing that a more negative attitude was associated with the possibility that prophylactic mastectomy would involve a significant financial burden.

Forty-four participants (38\%) responded positively regarding their willingness to consider contralateral prophylactic mastectomy if it was already necessary to perform a single mastectomy, and one participant (1\%) stated that they would be sure to receive a contralateral mastectomy. A total of 45 respondents (39\%) showed a positive attitude toward contralateral prophylactic mastectomy, whereas 37 respondents (32\%) stated that they were willing to undergo prophylactic mastectomy if they had a high risk of breast cancer.

A total of 45 respondents (39\%) reported a positive response regarding their willingness to consider breast reconstruction after prophylactic mastectomy, and 46 (40\%) stated that they would be were sure to undergo breast reconstruction. Thus, a total of 91 respondents (79\%) demonstrated a positive attitude toward breast reconstruction after prophylactic mastectomy (Table 3).

Attitudes toward genetic testing varied according to education level: 69 of 95 high school and college graduates $(73 \%)$ showed a positive attitude toward genetic testing, whereas 15 of 18 elementary and middle school graduates $(83 \%)$ showed a negative attitude toward it (Table 4).

Attitudes toward prophylactic mastectomy given a high risk of breast cancer also varied by education level: 35 of 95 high school

Table 2. Respondents' general knowledge of prophylactic mastectomy

\begin{tabular}{|lccccc|}
\hline Survey topics & $\begin{array}{c}\text { Never heard } \\
\text { of it }\end{array}$ & $\begin{array}{c}\text { Heard about it } \\
\text { once }\end{array}$ & $\begin{array}{c}\text { Basic } \\
\text { knowledge }\end{array}$ & $\begin{array}{c}\text { Detailed } \\
\text { knowledge }\end{array}$ & $\begin{array}{c}\text { Total } \\
\text { Prophylactic mastectomy }\end{array}$ \\
Hereditary breast cancer & 37 & 52 & 9 & 31 & 7 \\
Effectiveness of prophylactic mastectomy & 51 & 43 & 19 & 8 & 115 \\
Complications of prophylactic mastectomy & 58 & 45 & 13 & 0 & 115 \\
\hline
\end{tabular}

Table 3. Respondents' attitudes toward prophylactic mastectomy

\begin{tabular}{|c|c|c|c|c|c|}
\hline Survey topics & $\begin{array}{l}\text { Would never } \\
\text { undergo }\end{array}$ & $\begin{array}{l}\text { Negative attitude } \\
\text { (unlikely to consider) }\end{array}$ & $\begin{array}{l}\text { Positive attitude } \\
\text { (likely to consider) }\end{array}$ & $\begin{array}{l}\text { Would be sure to } \\
\text { undergo }\end{array}$ & Total \\
\hline Genetic test (e.g., BRCA1/2) & 4 & 39 & 61 & 11 & 115 \\
\hline Prophylactic mastectomy given high risk of breast cancer & 16 & 62 & 31 & 6 & 115 \\
\hline $\begin{array}{l}\text { Expensive prophylactic mastectomy, costing } 10 \text { million won } \\
\text { or more }\end{array}$ & 29 & 72 & 11 & 3 & 115 \\
\hline $\begin{array}{l}\text { Contralateral prophylactic mastectomy when undergoing a } \\
\text { single mastectomy }\end{array}$ & 23 & 47 & 44 & 1 & 115 \\
\hline $\begin{array}{l}\text { Breast reconstruction after receiving prophylactic } \\
\text { mastectomy }\end{array}$ & 9 & 15 & 45 & 46 & 115 \\
\hline
\end{tabular}


Table 4. Effects of education level on the preventive treatment of breast cancer

\begin{tabular}{|c|c|c|c|c|c|}
\hline \multirow[b]{2}{*}{$\begin{array}{l}\text { Education } \\
\text { level }\end{array}$} & \multicolumn{5}{|c|}{ Genetic testing (e.g., BRCA1/2) } \\
\hline & $\begin{array}{c}\text { Would } \\
\text { never } \\
\text { undergo }\end{array}$ & $\begin{array}{l}\text { Negative } \\
\text { attitude } \\
\text { (unlikely to } \\
\text { consider) }\end{array}$ & $\begin{array}{l}\text { Positive } \\
\text { attitude } \\
\text { (likely to } \\
\text { consider) }\end{array}$ & $\begin{array}{c}\text { Would } \\
\text { be sure } \\
\text { to } \\
\text { undergo }\end{array}$ & Total \\
\hline Elementary school & 3 & 2 & 1 & 0 & 6 \\
\hline Middle school & 0 & 10 & 2 & 0 & 12 \\
\hline High school & 0 & 9 & 14 & 0 & 23 \\
\hline College & 0 & 17 & 44 & 11 & 72 \\
\hline Others & 1 & 1 & 0 & 0 & 2 \\
\hline Total & 4 & 39 & 61 & 11 & 115 \\
\hline
\end{tabular}

Table 5. Effects of education level on the preventive treatment of breast cancer

\begin{tabular}{|lccccr|}
\hline & \multicolumn{5}{c|}{$\begin{array}{c}\text { Prophylactic mastectomy given high risk of } \\
\text { breast cancer }\end{array}$} \\
\cline { 2 - 6 } & $\begin{array}{c}\text { Would } \\
\text { never } \\
\text { undergo }\end{array}$ & $\begin{array}{c}\text { Negative } \\
\text { attitude } \\
\text { (unlikely to } \\
\text { consider) }\end{array}$ & $\begin{array}{c}\text { Positive } \\
\text { attitude } \\
\text { (likely to } \\
\text { consider) }\end{array}$ & $\begin{array}{c}\text { Would be } \\
\text { sure to } \\
\text { undergo }\end{array}$ & Total \\
\hline Elementary school & 4 & 2 & 0 & 0 & 6 \\
Middle school & 7 & 4 & 0 & 1 & 12 \\
High school & 5 & 8 & 9 & 1 & 23 \\
College & 0 & 47 & 21 & 4 & 72 \\
Others & 0 & 1 & 1 & 0 & 2 \\
Total & 16 & 62 & 31 & 6 & 115 \\
\hline
\end{tabular}

Table 6. Effects of marital status among women on the preventive treatment of breast cancer

\begin{tabular}{|lccccc|}
\hline & \multicolumn{5}{c|}{$\begin{array}{c}\text { Prophylactic mastectomy given a high risk of } \\
\text { breast cancer }\end{array}$} \\
\cline { 2 - 6 } $\begin{array}{c}\text { Marital } \\
\text { status }\end{array}$ & $\begin{array}{c}\text { Would } \\
\text { never } \\
\text { undergo }\end{array}$ & $\begin{array}{c}\text { Negative } \\
\text { attitude } \\
\text { (unlikely to } \\
\text { consider) }\end{array}$ & $\begin{array}{c}\text { Positive } \\
\text { attitude } \\
\text { (likely to } \\
\text { consider) }\end{array}$ & $\begin{array}{c}\text { Would be } \\
\text { sure to } \\
\text { undergo }\end{array}$ & Total \\
\hline Unmarried & 5 & 28 & 1 & 0 & 34 \\
Married & 1 & 14 & 15 & 1 & 31 \\
Total & 6 & 42 & 16 & 1 & 65 \\
\hline
\end{tabular}

and college graduates (37\%) showed a positive attitude toward prophylactic mastectomy, whereas 17 of 18 elementary and middle school graduates (94\%) showed a negative attitude toward it (Table 5).

Attitudes toward prophylactic mastectomy varied according to marital status. One of 34 unmarried female respondents (3\%) showed a positive attitude toward prophylactic mastectomy, compared to 16 of 31 married female respondents (51\%) (Table 6).

The most common reason for refusing to undergo prophylactic mastectomy, even given a high risk of breast cancer, was aesthetic concerns ( 44 respondents; $38 \%$ ), followed by the surgical
Fig. 1. Reasons for refusing to undergo prophylactic mastectomy

The most common reason for refusing to undergo prophylactic mastectomy despite a high risk of breast cancer was aesthetic concerns (44 persons; 38\%), followed by the surgical risk, the perception that prophylactic mastectomy leads to incomplete prevention, and the expense of the procedure.

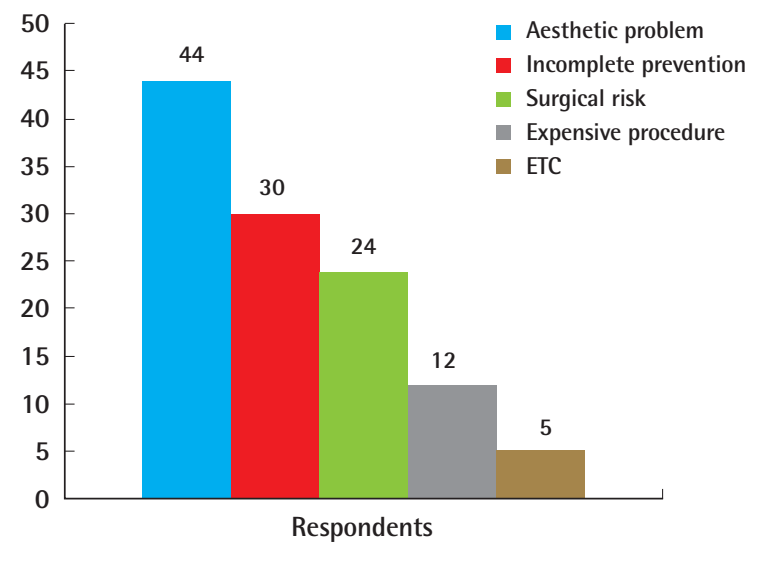

\section{Fig. 2. Ways of obtaining knowledge}

Most respondents obtained information via the mass media, followed by magazines or books and hospital materials.

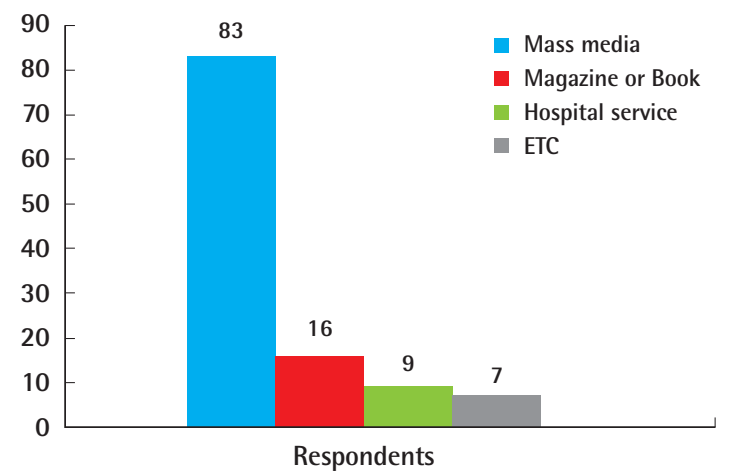

risk, the perception that prophylactic mastectomy would provide incomplete prevention, and the expense of the procedure (Fig. 1).

Most respondents had obtained their information via the mass media, followed by magazines or books, and materials provided by the hospital (Fig. 2).

\section{DISCUSSION}

Although prophylactic mastectomy is an irreversible operation, it is an aggressive method capable of reducing the risk of breast cancer by up to $89.5 \%$ [4]. Breast reconstruction generally accompanies prophylactic mastectomy, which may involve skinsparing mastectomy or nipple-areolar complex-sparing mastec- 
tomy. Breast reconstruction is often performed immediately after skin-sparing mastectomy because it has been reported to be aesthetically effective and to result in a lower risk of local recurrence.

Prophylactic mastectomy is also effective in preventing breast cancer in patients with either the BRCA1 or the BRCA2 mutation. In Korea, the BRCA1 and BRCA2 mutations account for approximately $2.5 \%-3.1 \%$ of patients with nonhereditary specific breast cancer (average, 2.6\%). If a person has a family history of breast and/or ovarian cancer, the incidence of the BRCA1 and BRCA2 mutation depends on the details of the family history. The $B R C A$ mutations account for approximately $19.4 \%-$ $22.1 \%$ of hereditary breast and/or ovarian cancer in patients with one family members with a history of breast and/or ovarian cancer. However, in cases where more than two family members have had breast and/or ovarian cancer, the likelihood of a BRCA mutation increases to $19.4 \%-42.9 \%$. In Korea, some notable clinical features of breast cancer are that patients are affected when they are 10-15 years younger than comparable patients in the West, and the proportion of patients younger than 35 years old is higher $[8,9]$.

The survival rate of $B R C A 1$ and $B R C A 2$ mutation carriers after prophylactic mastectomy depends on the occurrence of breast cancer, its stage, the infiltration rate of the $B R C A$ genes, and age of the carriers at the time of preventive surgery. The survival rate of normal carriers has reportedly been increased by up to 7.6 years when both prophylactic mastectomy and oophorectomy are performed when patients are in their thirties $[9,10]$. The use of prophylactic mastectomy varies globally by country as well as from study to study, and prophylactic mastectomy has reportedly been performed on $0 \%-54 \%$ of carriers [11]. The first case of prophylactic mastectomy in Korea was a contralateral prophylactic mastectomy performed along with oophorectomy in 2008 [12]. However, prophylactic mastectomy is not routinely performed in Korea [13].

The results of this study demonstrated that most respondents have no basic knowledge of prophylactic mastectomy or its effectiveness and complications. Fifteen years have passed since the discovery of the BRCA1 and BRCA2 mutations, and many studies have been performed in Western countries to assess the frequency of these mutations and to identify the gene regulator implicated in cancer caused by these mutations [14]. On the basis of such studies, models for predicting the likelihood of genetic mutations before testing have been developed, such as the Myriad and BRCAPRO models [15]. Accordingly, Western societies, including the United States, are becoming more knowledgeable and aware of genetic testing and prophylactic mastectomy. It is therefore necessary to conduct further research, such as the recent Korean Hereditary Breast Cancer study, in order to provide prevention and treatment to Koreans with a high risk of breast cancer.

In this study, most respondents reported a positive attitude toward genetic testing. However, they still tended to have a negative attitude toward prophylactic mastectomy. Although prophylactic mastectomy is an effective therapeutic method for patients with a high risk of breast cancer, Koreans still seem to have a negative attitude toward prophylactic mastectomy. This phenomenon is likely due to poor knowledge of the effectiveness of and indications for prophylactic mastectomy.

In contrast, a total of 45 participants (39\%) gave positive answers about undergoing contralateral prophylactic mastectomy along with a single mastectomy, with 44 respondents (38\%) indicating that they would consider it. This result is more positive than the results for undergoing prophylactic mastectomy with a high risk of breast cancer. In Korea, it is in practice difficult to check the results of genetic testing preoperatively. In Western societies, medical guidelines have suggested administering preoperative anticancer therapy to patients diagnosed with breast cancer who require genetic testing, and then presenting the results of genetic testing at the time of surgery so that preventive surgery can also be performed if desired [16]. Therefore, it would also be possible to consider contralateral prophylactic mastectomy in the patients diagnosed with breast cancer if adequate program of genetic testing is established in Korea and if appropriate medical guidelines are adopted.

A total of 91 participants (79\%) gave positive answers regarding undergoing breast reconstruction following prophylactic mastectomy, with 45 respondents (39\%) indicating that they would consider it. The most common reason for refusing to undergo prophylactic mastectomy even if a high risk of breast cancer was found, was aesthetic concerns (44 respondents; 38\%). This result demonstrates that Koreans are concerned with the aesthetic consequences of prophylactic mastectomy and suggests that they need an improved understanding of the effectiveness and complications of breast reconstruction. In addition, prophylactic mastectomy can place a financial burden on patients because it is not covered by the Korean health insurance system. Additional efforts should be made to solve this problem.

Out of 95 high school and college graduates, 69 respondents (73\%) showed a positive attitude toward genetic testing, whereas only three of the 18 (17\%) elementary and middle school graduates showed a positive attitude toward it. Of the 95 high school and college graduates, 35 respondents (37\%) showed a positive attitude toward prophylactic mastectomy if they were found to have a high risk of breast cancer, whereas 17 of 18 (94\%) elementary and middle school graduates showed a negative attitude toward it. These results indicate that attitudes toward both 
genetic testing and prophylactic mastectomy varied according education level. It is therefore necessary to provide information and education both through mass media and at hospitals, with the goal of preventing educational inequities in healthcare distribution.

Attitudes toward prophylactic mastectomy varied according to marital status: one of 34 unmarried female respondents (3\%) showed a positive attitude toward prophylactic mastectomy, compared to 16 of 31 (51\%) married female respondents. This result implies that attitudes toward this procedure depend both on aesthetic concerns before marriage and breastfeeding after marriage. Therefore, in hospitals, full consideration of patients' marital status and family relationships is necessary.

In this study, most respondents were found to have a low level of knowledge about prophylactic mastectomy. We found that 99 respondents ( $86 \%$ ) had no basic knowledge about prophylactic mastectomy. Only 37 respondents (32\%) were willing to undergo prophylactic mastectomy if they were found to have a high risk of breast cancer. Patients at a high risk of breast cancer have the basic indication for prophylactic mastectomy, although the decision may depend on personal conditions. Taking this into account, active research into and the development of educational materials concerning prophylactic mastectomy and hereditary breast cancer are necessary. Ultimately, it will be necessary to establish medical guidelines for patients at a high risk of breast cancer, with the objective of providing accurate information and proper treatment at hospitals.

This study had some limitations. The results would have been more statistically significant with a larger sample size. In addition, no information was gathered regarding each respondent's underlying diseases and genetic background. Future studies are likely to obtain more significant results with a larger sample size and the addition of other items to the questionnaire.

This is the first study to investigate perceptions of prophylactic mastectomy in Korea. Currently, attitudes toward medical treatment are being influenced by Western values, and people are becoming increasingly informed about medical issues. This study can therefore be considered valuable data that can inform the development of treatment strategies for patients with a high risk of breast cancer.

\section{REFERENCES}

1. Korean Breast Cancer Society. Breast cancer facts \& figures, 2013. Seoul: Korean Breast Cancer Society; 2013.

2. Claus EB, Schildkraut JM, Thompson WD, et al. The genetic attributable risk of breast and ovarian cancer. Cancer 1996; 77:2318-24.
3. Rebbeck TR, Lynch HT, Neuhausen SL, et al. Prophylactic oophorectomy in carriers of BRCA1 or BRCA2 mutations. N Engl J Med 2002;346:1616-22.

4. Hartmann LC, Schaid DJ, Woods JE, et al. Efficacy of bilateral prophylactic mastectomy in women with a family history of breast cancer. N Engl J Med 1999;340:77-84.

5. Lostumbo L, Carbine NE, Wallace J. Prophylactic mastectomy for the prevention of breast cancer. Cochrane Database Syst Rev 2010;(11):CD002748.

6. See HT, Cheung YB, Yong F, et al. Acceptance of prophylactic surgery and chemoprevention of cancer in Singapore: a survey. Ann Acad Med Singapore 2005;34:238-42.

7. Stefanek ME, Helzlsouer KJ, Wilcox PM, et al. Predictors of and satisfaction with bilateral prophylactic mastectomy. Prev Med 1995;24:412-9.

8. Son $\mathrm{BH}, \mathrm{Ahn} \mathrm{SH}$, Lee $\mathrm{MH}$, et al. Hereditary breast cancer in Korea: a review of the literature. J Breast Cancer 2008;11: 1-9.

9. Schrag D, Kuntz KM, Garber JE, et al. Decision analysis: effects of prophylactic mastectomy and oophorectomy on life expectancy among women with BRCA1 or BRCA2 mutations. N Engl J Med 1997;336:1465-71.

10. Schrag D, Kuntz KM, Garber JE, et al. Life expectancy gains from cancer prevention strategies for women with breast cancer and BRCA1 or BRCA2 mutations. JAMA 2000;283:61724.

11. Scheuer L, Kauff N, Robson M, et al. Outcome of preventive surgery and screening for breast and ovarian cancer in BRCA mutation carriers. J Clin Oncol 2002;20:1260-8.

12. Kim KS, Kim S, Han SA, et al. Contralateral prophylactic mastectomy and prophylactic salphingo-oophorectomy in a BRCA1-Positive breast cancer patient: a case report. J Breast Cancer 2008;11:218-22.

13. Kim KS, Kim SW, Lee MH, et al. Practice patterns of surgeons for the management of hereditary breast cancer in Korea. J Breast Cancer 2008;11:95-101.

14. Chenevix-Trench G, Milne RL, Antoniou AC, et al. An international initiative to identify genetic modifiers of cancer risk in BRCA1 and BRCA2 mutation carriers: the Consortium of Investigators of Modifiers of BRCA1 and BRCA2 (CIMBA). Breast Cancer Res 2007;9:104.

15. Parmigiani G, Berry D, Aguilar O. Determining carrier probabilities for breast cancer-susceptibility genes BRCA1 and BRCA2. Am J Hum Genet 1998;62:145-58.

16. Silva E. Genetic counseling and clinical management of newly diagnosed breast cancer patients at genetic risk for BRCA germline mutations: perspective of a surgical oncologist. Fam Cancer 2008;7:91-5. 